\title{
A Novel Dual Inductor DC-DC Buck Converter
}

\author{
Sairatun Nesa Soheli ${ }^{1}$, Md Saidur Rahman ${ }^{2}$, Khadiza Akter $^{3}$ \\ ${ }^{1}$ Lecturer of Electrical and Electronics Engineering, IUBAT-International University of Business Agriculture and \\ Technology, Uttara, Dhaka, Bangladesh \\ ${ }^{2}$ Senior Lecturer of Computer Science and Engineering, IUBAT-International University of Business \\ Agriculture and Technology, Uttara, Dhaka, Bangladesh \\ ${ }^{3}$ Lecturer of Electrical and Electronics Engineering, IUBAT-International University of Business Agriculture and \\ Technology, Uttara, Dhaka, Bangladesh
}

\begin{abstract}
A novel DC-DC Buck Converter using dual inductor and switched capacitor is proposed. Proposed circuit consists of two inductor instead of single inductor used in conventional dc-dc buck converter. The proposed converter offers better efficiency in obtaining same low voltage gain. Energy is effectively transferred from source to load using one inductor and capacitor while other inductor is used to step down the voltage and also get better efficiency than conventional dc-dc buck converter. In switch on time period the two inductors are in parallel and in off time period the two inductors are in series, on that time two inductors charged the output capacitor to get better efficiency. Simulation results verified the high efficiency three-stage operation of the proposed converter.
\end{abstract}

Keywords: Dual inductor, Switched capacitor, DC-DC Buck Converter

\section{Introduction}

Power converter plays a very major role in wide range of applications of power electronics. SMPS (Switched Mode Power Supply) converters are very important in sense of ease of application \& scope of improvement. A dc-dc buck converter is a power converter which is step down the voltage, while stepping up the current from its input to output. It is a class of SMPS (Switched Mode Power Supply) typically containing at least a diode and a transistor, although modern buck converters frequently replace the diode with a second transistor used for synchronous rectification and at least one energy storage element, a capacitor, inductor, or the two in combination [1,2]. To reduce voltage ripple, filters made of capacitors are normally added to such a converter's output and input. DC-DC converters provide much greater power efficiency than linear regulators, which are simpler circuits that lower voltages by dissipating power as heat, which does not step up output current $[3,4]$.

The basic operation of the buck converter has the current in an inductor controlled by two switches, usually a transistor and a diode. In the idealized converter, all the components are considered to be perfect. Specifically, the switch and the diode have zero voltage drop when on and zero current flow when off and the inductor has zero series resistance. Further, it is assumed that the input and output voltages do not change over the course of a cycle. This would imply the output capacitance as being infinite. The buck converter is best understood in terms of the relation between current and voltage of the inductor. Beginning with the switch open, the current in the circuit is zero. When the switch is first closed, the current will begin to increase, and the inductor will produce an opposing voltage across its terminals in response to the changing current. This voltage drop counteracts the voltage of the source and therefore reduces the net voltage across the load. Over time, the rate of change of current decreases, and the voltage across the inductor also then decreases, increasing the voltage at the load.

Buck converter aims at efficiencies higher than a linear regulator for a large range of the output current [5]. If the generated voltage Vout is D times the supply voltage, the efficiency of the linear regulator is D. Therefore, the goal is to keep system efficiency well above D for an extended range of output current. Just obtaining very high switching frequency $[6,7]$ is not practical. The goal of this design is to achieve for I-A output current, efficiency higher than what reported in published research results $[8,9]$.

The proposed DC-DC Buck Converter comprises a DC input voltage, active power switch, dual inductor, three diodes, one output capacitor respectively. This proposed converters use a pair of switches, usually one controlled (e.g. MOSFET) and one uncontrolled (i.e. diode), to achieve unidirectional power flow from input to output. The converters also use one capacitor and one inductor to store and transfer energy from input to output. Another inductor uses to get better efficiency than conventional dc-dc buck converter.

DC-DC converters can be operated either in continuous conduction mode (CCM) or in discontinuous conduction mode (DCM). DC-DC converters that operated in DCM provide faster transient response (due to its low inductance) at the expense of higher device stresses. A fixed frequency PWM based sliding mode controllers for dc-dc converters operating in DCM $[10,11]$. Buck converter when operated in CCM, gives a continuous output current, with smaller current ripple and low switching noise. CCM operation is usually preferred for large 
current applications, because it can deliver more current than the converter operating in DCM. However, a DCM converter has a much faster transient response and a loop gain that is easier to compensate than a CCM converter. Hence, for fulfill of both the requirements, a new converter that combines the advantage of both CCM and DCM converters is developed. CCM buck converter has much improved current handling capability with reduced current and voltage ripple [12]. For this proposed circuit only consider the DC-DC Buck Converters operated in CCM.

\section{Operating Principle}

In DC-DC Converters, the average dc output voltage must be controlled to equal a desired level, though the input voltage and the output load fluctuate. Switch-mode dc-dc converters utilize one or more switches to transform dc from one level to another. In dc-dc converters with a given input voltage, the average output voltage is controlled by controlling the switch on and off duration. The average value of the output voltage depends on the switch on and off duration. Basic DC-DC Buck Converter comprises a DC input voltage, active power switch, one inductor, one diode and one capacitor respectively. Buck converters can be remarkably efficient, higher than $90 \%$.

The circuit configuration of the proposed DC-DC Buck Converter is shown in Fig. 1. It comprises a DC input voltage (Vin), active power switch $(S)$, dual inductor $(L 1 \& L 2)$, three diodes $(D 1, D 2 \& D 3)$, capacitor $(C L)$ respectively. The capacitor $(C L)$ is employed as an output capacitor with the value of $200 \mu F$ which store the energy. Inductor $(L 1)$ with the value of $66 \mathrm{mH}$, employed to store and transfer energy from input to output. They also filters or smooth voltage and current. Another inductor (L2) with the value of $66 \mathrm{mH}$ is used to get better efficiency than conventional dc-dc buck converter.

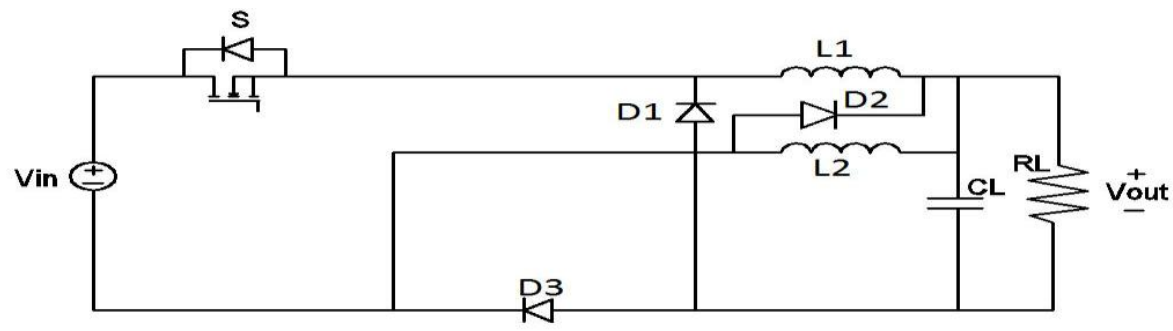

Fig. 1. Circuit configuration of proposed converter

In order to simplify the circuit analysis of the converter, some assumptions are considered as follow:

1. The capacitor is sufficiently large. Therefore $V C$ and Vout are considered being constant during one switching period.

2. All components are ideal.

According to the assumptions, the CCM operation of the proposed converter includes three intervals one switching period. The current flow path of the proposed converter for each stage is depicted in Fig. 2. The operating stages are explained as follows:

1) Stage I: In this stage the switch is turned on. Also diode $D 3$ is turned on and diode $D 1 \& D 2$ are turned off. The DC source $(V I)$ for a time duration DT, the switch $(S)$ conduct inductor $(L 1)$ current, diode $(D 3)$ current and another two diodes $(D 1 \& D 2)$ becomes reverse biased. The required energy of load $(R L)$ is supplied by the output capacitor $(C L)$. Again the DC source $(V 1)$ for time duration DT, the switch $(S)$ conducts inductors $(L 1 \& L 2)$ currents and another two diodes (D1 \& D2) becomes reverse biased, shown in Fig. 2(a). This result is in positive voltage $V L$ across the inductor $(L 2)$. This voltage causes a linear increase in the inductor current $i L$.

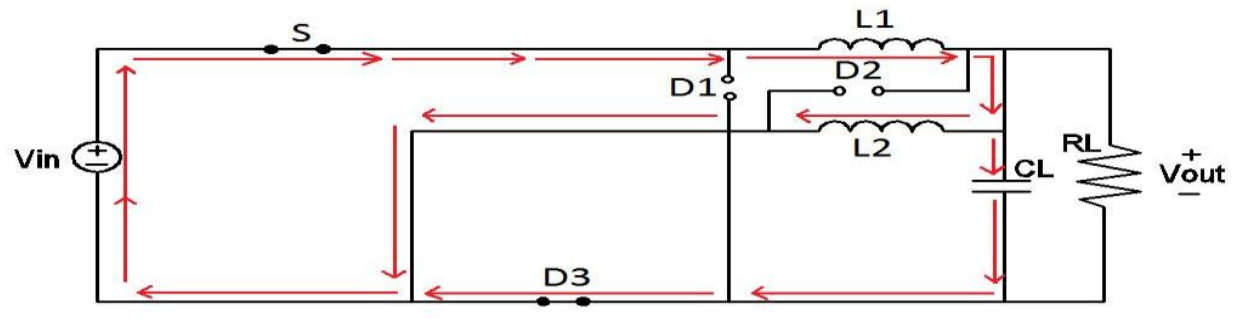

Fig 2(a). Switch on period 
2) Stage II: In this stage the switch is turned off. Also diode $D 2$ is tuned off and diode $D 1$ is turned on because of the inductive energy storage, $i L 1=i L$ continuous to flow. This current now flows through the capacitor $(C L)$ and diode $(D 1)$. There is no current flow in the another inductor $(L 2)$, shown in Fig. 2(b) for a time duration (1-D)T until the switch is turned on again.

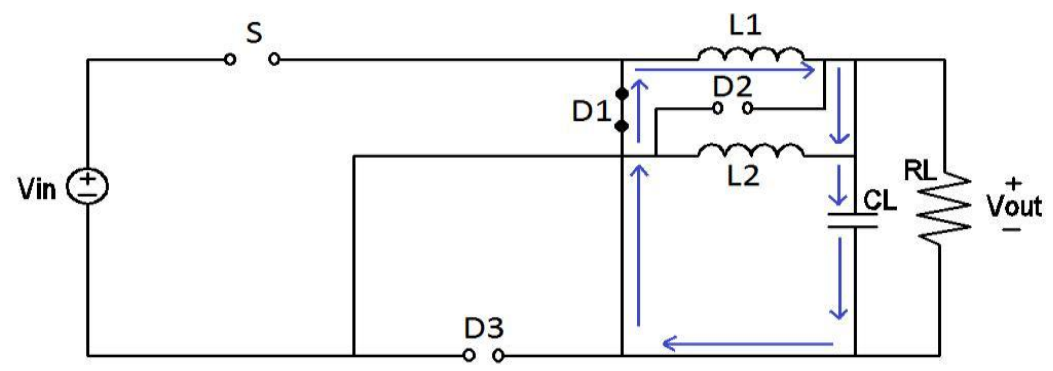

Fig.2(b). Switch off period

\section{Steady-State Operation Of The Proposed Converter}

To simplify the steady state analysis during the time when switch is on, the following equation can be written according to Fig. 2(a):

Vin - VL1 - Vout $=0$

Vin - Vout $=$ VL1---------(i)

Now, from the following equation can be written according to Fig. 2(b):

$\operatorname{Vin}-V L 1-V L 2=0$

$V i n=V L 1+V L 2$

Vin $=2 V L 1$

From the Fig. 1, it is known that the values of inductor $L 1$ and $L 2$ are same. So, we can say from there, that -

$V L 1=V L 2$

Now adding equation (i) and (ii), we can get -

$V L 1=(2$ Vin - Vout $) / 3$

This result is in positive voltage, $V L=V L 1=(2$ Vin - Vout $) / 3$

When switch is off, the following equation can be written according to Fig.2(c):

$-V L 1-$ Vout $=0$

$V L 1=V L=-$ Vout zero yields to the

Equating the integral of inductor voltage over one time period 


$$
\begin{aligned}
& \int_{0}^{T} V_{L} d t=\int_{0}^{t_{\text {on }}} V_{1} d t+\int_{0}^{t_{\text {off }}} V_{L} d t=0 \\
& \frac{\left\{\left(2 V_{\text {in }}-V_{\text {out }}\right) * D T\right\}}{3}+\left\{\left(-V_{\text {out }}\right) *(1-D) T\right\}=0
\end{aligned}
$$$$
\frac{2 V_{\text {in }} D T-V_{\text {out }} D T}{3}-V_{\text {out }} T+V_{\text {out }} D T=0
$$$$
\frac{2 V_{\text {in }} D T-V_{\text {out }} D T-3 V_{\text {out }} T+3 V_{\text {out }} D T}{3}=0
$$

$2 \mathrm{~V}_{\text {in }} \mathrm{DT}-2 \mathrm{~V}_{\text {out }} \mathrm{DT}-3 \mathrm{~V}_{\text {out }} \mathrm{T}=0$

$2 \mathrm{~V}_{\text {in }} \mathrm{DT}-2 \mathrm{~V}_{\text {out }} \mathrm{DT}=3 \mathrm{~V}_{\text {out }} \mathrm{T}$

$2 \mathrm{~V}_{\text {in }} \mathrm{D}-2 \mathrm{~V}_{\text {out }} \mathrm{D}=3 \mathrm{~V}_{\text {out }}$

$2 V_{\text {in }} D=3 V_{\text {out }}+2 V_{\text {out }} D$

$2 V_{\text {in }} D=V_{\text {out }}(3+2 D)$

$$
G=\frac{2 D}{3+2 D}
$$

The voltage gain of this proposed circuit is-

\section{Performance Of The Proposed Circuit}

The simulation of the proposed circuit is performed using PSIM and the results obtained are presented in Table 2. The source is a DC source with input voltage $1200 \mathrm{~V}$ because of to take better efficiency than conventional. The switching frequency of the power switch has been set to $8 \mathrm{KHz}$ and an MOSFET Switch is considered as the switching device. The circuit is simulated with the component $L 1 \& L 2$ as $66 \mathrm{mH}$, output filter capacitor $C L$ as $200 \mu F$ and load resistance $R L$ as $50 \Omega$. The proposed circuit has been compared with the conventional DC-DC basic buck using same circuit parameter values. The specifications of the implemented circuit are also given in Table 1. Typical results are presented in the next subsection.

Table 1 Spacifications Of The Implemented Parameters

\begin{tabular}{|l|l|}
\hline Specifications & Values \\
\hline Input DC Voltage & Vin $=1200 \mathrm{~V}$ \\
\hline & \\
\hline Output DC Voltage & Vout $=190 \mathrm{~V}$ \\
\hline & \\
\hline Inductor & $L 1=L 2=66 \mathrm{mH}$ \\
\hline & \\
\hline Capacitor & $C L=200 \mu \mathrm{F}$ \\
\hline & \\
\hline Resistor & $R L=50 \Omega$ \\
\hline & \\
\hline
\end{tabular}

\section{A. Result from Simulation:}

The typical wave shapes of input voltage and output voltage along with the spectrum of the input current for the proposed Buck based input side switched DC-DC converter is shown in Fig. 3. It is evident from the wave shapes obtained that the output voltage of the proposed Buck based DC-DC converter is almost DC signal.

The experimental results are shown in Fig. 3(a) where the input voltage $1200 \mathrm{~V}$ and we get the output voltage $190 \mathrm{~V}$. Currents through diodes $D 1, D 2 \& D 3$, inductor $L 1, L 2$, capacitor $C L$, resistor $R L$ are shown in Fig. $3(b), 3(c) \& 3(d)$. The results verify the analysis of the steady state operation. When switch is ON, the current conducts the dual inductors $(L 1 \& L 2)$ through capacitor $(C L)$ and diode $(D 4)$. When switch off, the inductor $L 1$ supplies the storage energy through the capacitor $(C L)$ and diode $(D 1)$. Then we get the output voltage $190 \mathrm{~V}$ and efficiency $98.279 \%$. 


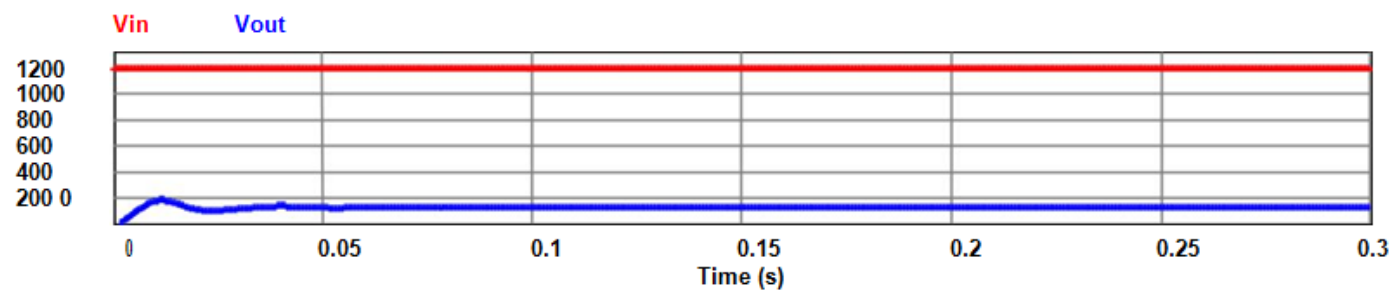

Fig. 3(a). Simulated Input and Output voltage of the proposed DC-DC Buck Converter
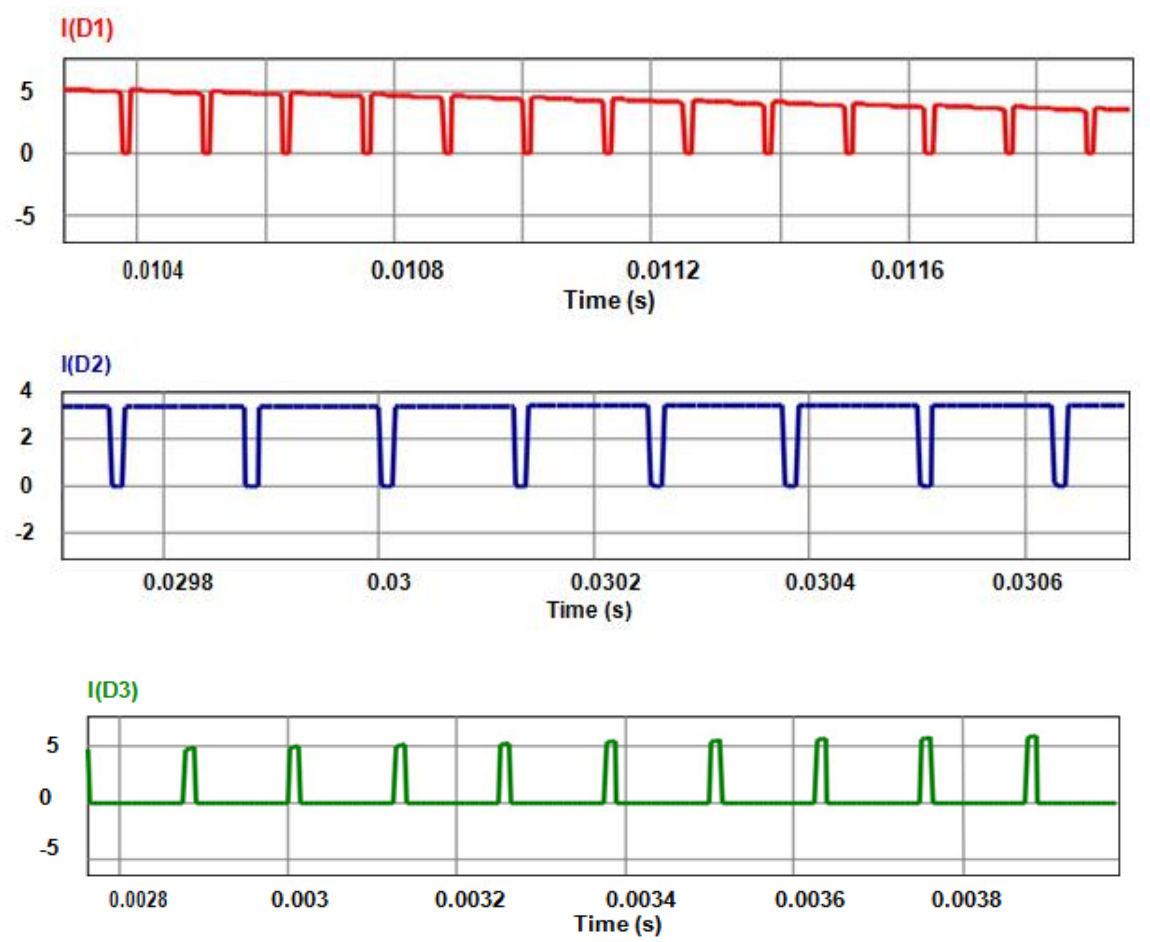

Fig. 3(b). Currents through diodes $D 1, D 2 \& D 3$
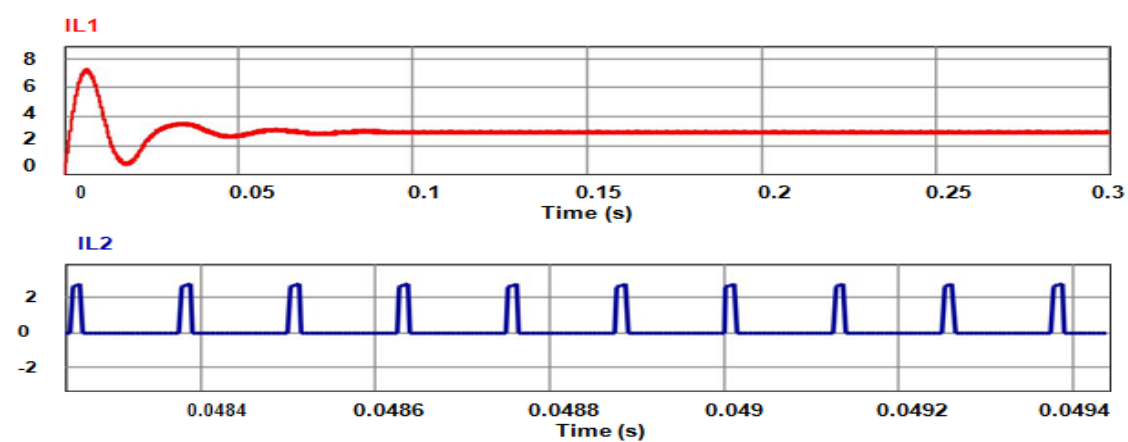

Fig. 3(c). Currents through inductors $L 1, L 2$
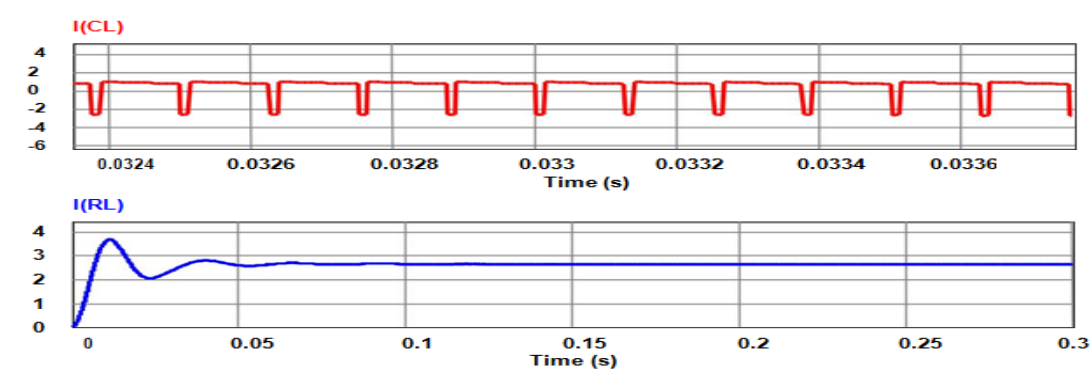

Fig. 3(d). Currents through capacitor $C L \&$ resistor $R L$ 


\section{B. Quantitative Comparison:}

Table II shows the comparative analysis of conventional circuit with the proposed circuit for switching frequency and load variation. Both the circuits are switched at $2 \mathrm{KHz}-20 \mathrm{KHz}$. It depicts that efficiency of the proposed step-down converter is much better for all the range of efficiency than conventional buck converter. In Table II the circuit performance under load variation is justified for both conventional and Buck based converter for the switching frequency of $8 \mathrm{KHz}$. It also depicts that efficiency of the proposed buck based converter is much better for all the range of efficiency than conventional buck converter. The bar chart shown in Fig. 4 (a) \& 4(b) indicates that the comparison of conventional and proposed circuit Efficiency verses switching frequency \& Efficiency verses load. Fig. 5 indicates the ratio between duty cycle and voltage gain for the proposed circuit.

Table 2 Performance Comparison Under Switching Frequency And Load Variation

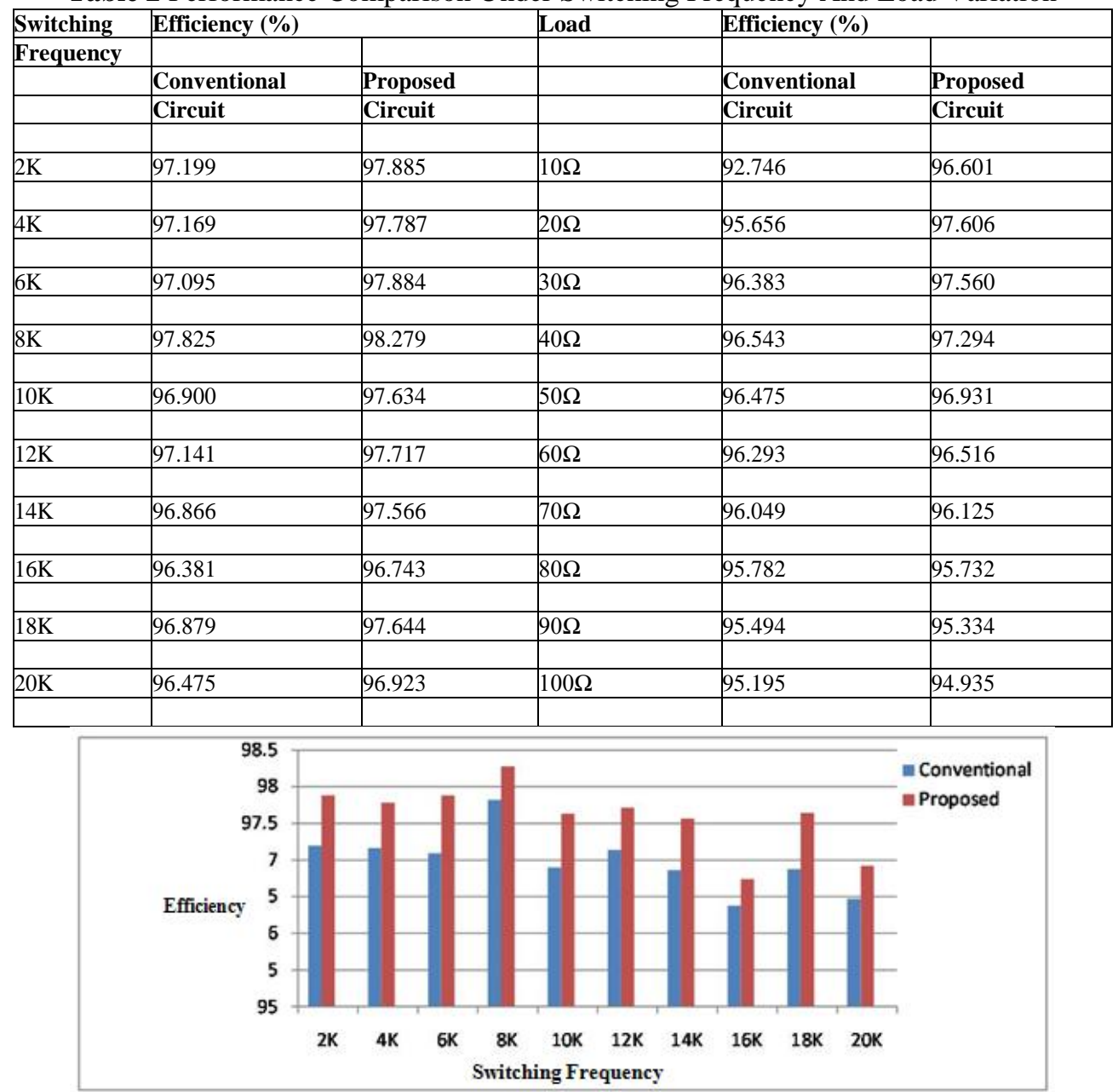

Fig. 4(a). Comparison of conventional and proposed circuit, Efficiency verses switching frequency

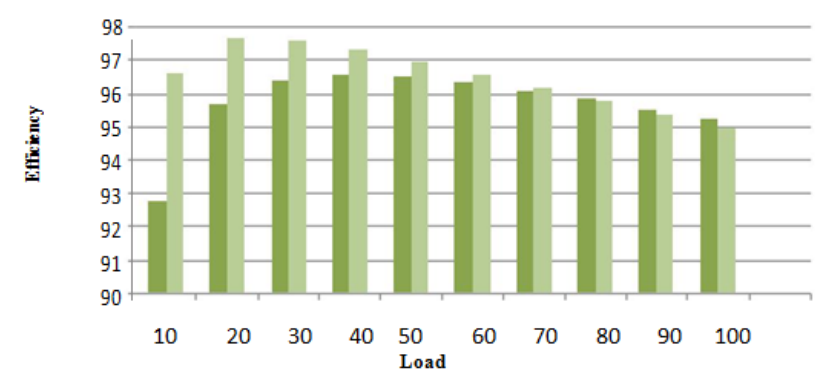

Conventional Proposed 
Fig. 4(b). Comparison of conventional and proposed circuit, Efficiency verses load

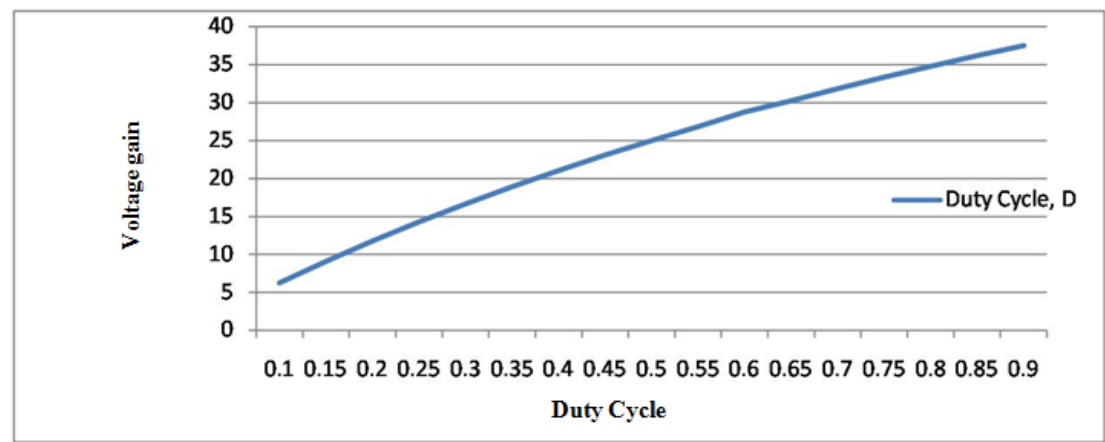

Fig. 5. Voltage gain of the proposed circuit throughout the duty cycle 0.1 to 0.9

\section{Conclusion}

The proposed DC-DC Buck Converter presents low output voltage with high efficiency by using dual inductor and switched capacitor. The energy stored in the inductor $(L 1)$ is recycled to improve the performance of the presented DC-DC Buck Converter. Furthermore, the loss of diode and power is reduced. The steady state operation of the proposed DC-DC Buck Converters has been analyzed in details. The results prove of feasibility of the presented DC-DC Buck Converter.

\section{Acknowledgements}

The work supported by IUBAT-International University of Business Agriculture and Technology.

\section{References}

[1]. Shafinaz A. Lopa, S. Hossain, M. K. Hasan, T. K. Chakraborty, "Design and Simulation of DC-DC Converters", International Research

[2]. Journal of Engineering and Technology (IRJET), Vol 03, issue 01, pp. 64-70, Jan 2016.

[3]. Cheng-Hui Chang, Robert C. Chang, "A novel current sensing circuit for a current-mode control CMOS DC-DC buck converter", 2005 IEEE VLSI-TSA International Symposium on VLSI Design, Automation and Test, 2005. (VLSI-TSA-DAT), pp. 120-123, April 2005.

[4]. S. Saggini, W. Stefanutti, P. Mattavelli, A. Carrera, "Efficiency Estimation in Digitally-Controlled dc-dc Buck Converters based on Single Current Sensing”, 2008 IEEE Power Electronics Specialists Conference, pp. 3581-3586, June 2008.

[5]. Gregory Sizikov, AvinoamKolodny, Eby G. Fridman, Michael Zelikson, "Efficiency optimization of integrated DC-DC buck converters", Electronics, Circuits, and Systems (ICECS), 2010 17th IEEE International Conference on, pp. 1208 - 1211, Dec 2010.

[6]. Betcy Mariam David, Sreeja K.K, “A Review of Sliding Mode Control Of DC-DC Converters", International Research Journal of

[7]. Engineering and Technology (IRJET), Vol 02, issue: 04, pp. 1382-1386, July 2015.

[8]. J. Wibben and R. Harjani, "A High-Efficiency DC-DC Converter Using 2 nH Integrated Inductors", IEEE J. ofSolidState Circuits, Vol 43, pp. 844-854, April 2008.

[9]. M. Wens and M. Steyaert, "A Fully-Integrated 130nm CMOS DC-DC Step-Down Converter, Regulated by a Constant On/OffTime Control System", Proc. of 2008 IEEE European Solid-State Circuits Conference, pp. 62-65, Sept 2008.

[10]. P. Hazucha, G. Schrom, 1. Hahn, B.A. Bloechel, P. Hack, G.E. Dermer, S. Narendra, D. Gardner, 1'. Kamik, V. Dc, and S. Borkar, "A 233-MI-1z 80\%-87\% Efficient Four-Phase DC-DC Converter Utilizing Air-Core Inductors on Package", IEEE J. of Solid-State Circuits, vol. 40, pp. 838-845, April 2005.

[11]. K. Onizuka, K. Inagaki, H. Kawaguchi, M. Takamiya, and T. Sakurai, "Stacked-Chip Implementation of On-Chip Buck Converter for Distributed Power Supply System in SiPs", IEEE J. Solid-State Circuits, vol. 42, pp. 2404-2410, Nov 2007.

[12]. S. C. Tan, Y. M. Lai, C. K. Tse, L. Martinez-Salamero, and A. Cid-Pastor, "Design of pulsewidth-modulation based sliding mode controllers for power converters operating in discontinuous conduction mode," IECON 2006 - 32nd Annual Conference on IEEE Industrial Electronics, pp. 2769 - 2774, Nov 2006.

[13]. S. C. Tan, Y. M. Lai, C. K. Tse, and L. Martinez-Salamero, "Special family of PWM based sliding mode voltage controllers for basic dc-dc converters in discontinous conduction mode," Electric Power Applications, vol. 1, issue 1, pp. 64-74, Jan 2007.

[14]. Zongqi Hu, Dongsheng Ma, "A pseudo-CCM buck converter with freewheel switching control," 2005 IEEE International Symposium on Circuits and Systems, Vol. 4, pp. 3083- 3086, May. 2005. 